\title{
EVALUATING THE IMAGE OF HEALTHCARE HUBS ONLINE - A CROSS SECTIONAL ANALYSIS OF GOOGLE AND FACE BOOK REVIEWS OF PRIVATE HOSPITALS OF KOLKATA, EASTERN INDIA
}

\author{
A. Rai ${ }^{1}$, \\ ${ }^{1}$ Adamas University, Department of Geography, Kolkata 700126, West Bengal, India - rai.anu405@ gmail.com
}

\section{Commission V, SS: Emerging Trends in Geoinformatics}

\begin{abstract}
KEY WORDS: medical tourism, medical tourists, crowd-sourced data, Google Place Review, Facebook Review, Kolkata, medical
\end{abstract} tourism information system, service quality

\begin{abstract}
:
The purpose of this paper is to map perceived image of major healthcare hubs of Kolkata, Eastern India. Kolkata as the gateway of Eastern India is a favourite destination among the migrating patients of South Asia while travelling outside the city to access better healthcare opportunity is the common among locales of the city. Acknowledging the significance of crowed-sourced platform and significance of social media data mining this study examines the differences among the perception between medical tourists and local visitors seeking healthcare at the major hospitals of the Kolkata, Eastern India. This study used both quantitative and qualitative data to identify the virtual image of the major healthcare hubs of the Kolkata. Through extensive field visit the major medical hubs of the city has been demarcated. The Google and Facebook reviews of these individual hospitals have been collected for the period $2013-$ 2017 for the detailed analysis. Perceptions of both inbound medical tourists and local visitors have been taken into consideration to evaluate the online image of the major medical tourism hubs of the city. The results reveals the significance of the social data mining in evaluating the quality healthcare infrastructure of the city. The growing field of medical tourism around the world has high demand for database to formulate public policy and to deliver high service quality to the medical travellers without compromising the need of neighbourhood community. This study uniquely highlights the dual role of internet and GIS that could together strengthen the medical tourism information system for the prospective consumer and at the same time provides significance of the crowd-sourced database with field validation that could be used by professionals and policy maker for sustenance of medical tourism which will strengthen the healthcare sector of the city in long run.
\end{abstract}

\section{INTRODUCTION}

\subsection{Social media in everyday live}

Since last three decades internet has becoming a solution to the problem of everyday lives while deep penetration of online social networks have brought about the digital revolution in the each and every sphere of our lives (Mariani, Mura and Felice, 2017). Online social networks (OSNs), a web based service that offer a platform to individuals to create a public/semi-public profile which can be used to communicate with the other users within the network. Facebook, Twitter, Instagram, and review sites like Google place reviews have created a vast space of communication to connect the global community where individual user is free of partially free to exchange their own idea with the members of the online community (Boyd and Ellison, 2008; Mariani, Mura and Felice, 2017). Social media empowers its users with the avalanche of useful information. It allows them to gather information, to connect with the community, to build relationships, to make decisions, to share experience or to rate the product and services on public platform (Ayeh, Au and Law, 2013). As social media allows users rather than producer in controlling internet content, people are becoming more dependent on the social network and making decisions based on the information posted by the unfamiliar Efriend on social network (Schegg et.al. 2008; Mariani, Mura and Felice, 2017).

\subsection{Medical tourism}

Increasing tendency among people to access opportunity of better medical care abroad is known as 'medical tourism' (Hunter, 2007; Turner 2007; Cook, 2010), a popular consumer
- driven internet search term (Munro, 2012). It is to be believed that much of the emergence of this $\$ 300$ billion medical tourism industry is credited primarily to internet searches, word of mouth recommendations and referrals (Ehrbeck and Guevera 2008; Tata, 2009). People are increasingly turning to the internet for health related information in fact internet has become first step in making decisions. One analysis estimates that approximately $4.5 \%$ of all searches on the web might be health related (Eysenbach and Kohler, 2003).

\section{3 eFriend - Dr. Google and Facebook}

Google and Face book with more than 1.5 billion global users offers one of the widely used platform that connects individuals and allow them to share their experience and hence constructing the virtual image of the product and services. Along with the millions of information available online against the barriers of traditional information seeking processes, Google place reviews and Facebook reviews empowers consumers with the widespread opportunities to more actively and independently manage their health care (Cortez, 2008).

On Google Maps, users can write reviews for places, they have visited. They can also leave info about a place or add their experience. This reviews and opinions are voluntary. Google does not pay reviewers for adding them to Google maps. No one can add anonymous review also. However all these reviews are public, so anyone can see what reviewers write. Such Google Place Reviews are very important for prospective visitors. Prospective medical tourism consumers can use these reviews before selecting final destination while researcher community may use these Google Reviews to evaluate the host - guest relationship of medical tourism destinations. 


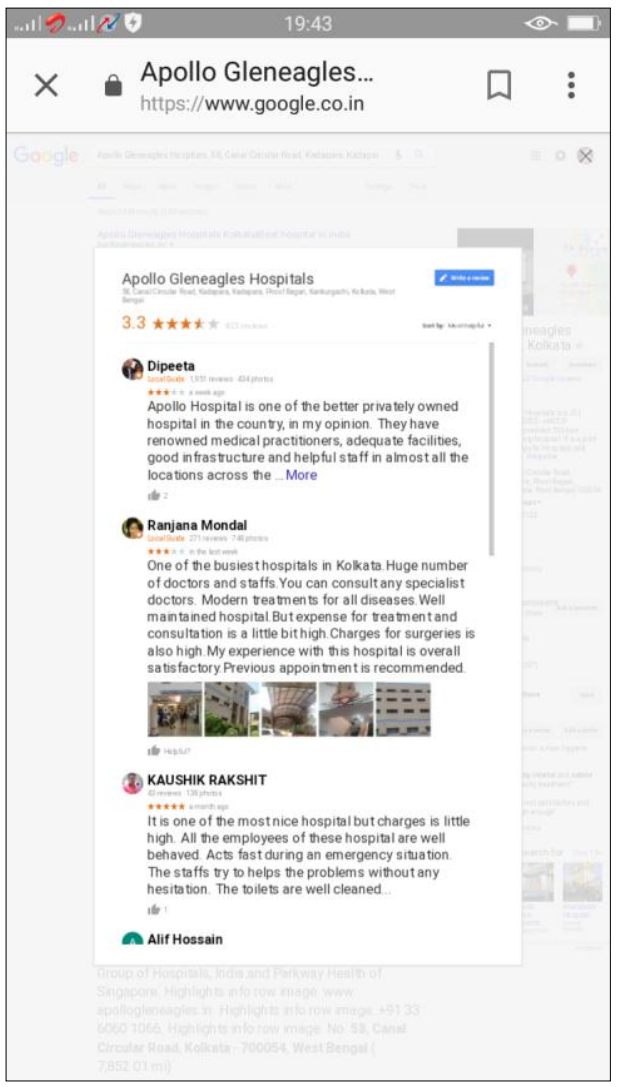

Figure 1. Google Place Reviews for Apollo Gleneagles Hospital, Search Result Page accessed on 29.01.2018

Figure 1 represents the Google Place Reviews for Apollo Gleneagles Hospital Kolkata. Review contains mean ratings given by patients or accompanied person visited Apollo Gleneagles Hospital, Kolkata. Users have also elaborated their experience which is used as a database in evaluating the service quality of at individual hospital level served to both local and medical tourist community.

With 2.27 billion monthly active user worldwide Face book is one of the biggest platform for sharing opinions and information. Over the years, face book has become one of the top social networking website (Edosomwan et. al., 2011). It is widely used by people of all ages and demographics (Anissa, 2017). In addition to customer reviews, Facebook is also used for one-on-one communication with existing customers, increasing the quality of the reviews you receive.

Based on the big data approach, this study assumes that in this age of online social networking individual is actively participating in expressing his or her experience related to medical trip, service quality and infrastructure at individual hospital level. This paper is an attempt to draw an attention of medical tourism researcher and suggest to use tools like Google Place Reviews Face book post reviews to unwrap the many hidden pages of medical tourism research considering microscale study. This paper uses Google and Face book reviews and attempts to understand the image of major healthcare hubs actively hosting inbound and domestic medical tourists throughout the year. With billions of users, present study believe that Google and face book offers reliable platform to evaluate the service quality of the individual hospital at micro level.

\subsection{Kolkata - medical tourism hub in Eastern India}

Kolkata, the capital city of West Bengal is one among the major hubs offering medical tourism services in India. It is the favourite destination among neighbouring and middle income countries (Rai, Chakraborty, \& Sarkar, 2014; Rai, 2019forthcoming). Being the major medical tourism hub Kolkata offers as quality health care standards through a set of a large number of private and public hospitals, well equipped with the latest technological world class facilities, well trusted and reputed doctors and specialists along with low cost of medical treatment and with suitable accommodation facilities (Rai, 2019-forthcoming). Most of the international patients, who come for treatment, are from the South Asian Association for Regional Cooperation (SAARC) nations or middle and low income countries (Rai, Chakraborty, \& Sarkar, 2014) while there is regular flow of domestic patients from the North Eastern states of India, Uttar Pradesh, Bihar, Jharkhand, Odisha etc. Considering the significance of the crowed sourced big data, present study attempts to delineate the online image of the healthcare hubs and adopts micro-scale study approach.

\section{DATABASE AND METHODOLOGY}

\subsection{Literature Review}

The relationship of internet and medical tourism one of the widely covered topic in the existing world of literature. Many scholars have made a significant attempt to unwrap the role of internet in evolution of medical tourism business. Moghavvemi, et. al., 2016 examines the websites of the private hospitals promoting medical tourism of the three countries in Asia. This paper studies how medical tourists and their decision making process are influenced by the online contents of these websites. For this purpose 51 private hospital websites were analysed. The result found that websites of private hospitals which are available online are very much crucial in boosting medical tourism especially to the foreign audiences (Moghavvemi, et. al., 2016). Similarly Foote (2017) founded that internet provides a medium of marketing for medical tourism providers and operators through advertisement of healthcare treatments and creates awareness about medical travel options to those seeking out information. Thus the presence of such a wide variety of online services and information in the internet helps to influence the decisions of the medical tourists to visit a particular destination or to opt a particular medical facility. Horsfall et al. 2013 acknowledges the popularity of medical tourism in the last decade as the contribution of wide availability of the information available online. Hallem \& Barth (2015) attempts to explore role of internet in context of medical tourist behaviour. Considering the significance of informational, social and relational function of the internet, this study concludes that internet is the foremost major information tool. Internet not only serves as the source of information but also performs its social function and offering specific space like Face book, Twitter, Google place reviews and many others dedicated for the exchange of the idea, information and experience where anyone can share his or her experience with the specific medical tourism location and interestingly anyone can use it as the source of information for their decision making.

Many attempts have also been made to evaluate the utilization and influence of such social plate form of information exchange 
(DiStaso, Vafeiadis and Amaral 2014). Ertugan (2017) identified how significantly facebook is integrated into the daily lives of its users. Liu et. al. (2017) examined the impact of the commercial communication social media strategy on users' electronic word-of-mouth behaviour through content analysis. It is also observed that social network has a great potential for information source and a source for knowledge dissemination for tourism industry to network and create clusters locally and globally (Mariania, Murab and Felicec, 2017). Medhekar (2017) evaluated the role of social media for knowledge dissemination in medical tourism.

\subsection{Database}

Acknowledging the significance of online reviews posted on Google and face book, it is assumed that prospective medical tourists will use the social media platform before selecting final destination irrespective of their nationality. As the social media offers open platform to its users, perceptions of both inbound medical tourists and local visitors have been taken into consideration. Hospital-wise review data from Google and Facebook was recorded during May 2017 to September 2017 that covered the review period from 2014 to 2017. Each record has been coded with the unique coding system to avoid any duplicacy. Each unique record includes the name of the reviwer, country of residence, name of the hospital visited for the treatment in Kolkata, time of visit, time of review posted, individual hospital rating and detailed comments in the form of the series of strings and texts has been recorded for the further analysis. Further to understand the field scenario in-detailed percpetion study of international patients and local patient community using structured and semi-structured questionnaire schedule have been carried out during Jan 2017 to Jun 2017.

\subsection{Samples and Sample Profile}

Using multipurpose random sampling techniques in total 21 hospitals were selected through multiple field visits in these locations and on the basis of their popularity among the patient groups.

\begin{tabular}{|l|r|}
\hline Samples & No. \\
\hline No. of Hospitals & 22 \\
Google Place Review & 4007 \\
Google Place Reviews - usable & 3628 \\
response with location information & \\
Facebook review & 1030 \\
$\begin{array}{l}\text { Facebook review - with usable } \\
\text { response with location information }\end{array}$ & 148 \\
\hline
\end{tabular}

Table 1: Sample Profile

For these 22 major healthcare hubs of the Kolkata, in total in total 5337 samples collected. For this particular paper further the samples with adequate information on location and who have posted reviews have been incorporated in the databse for the further analysis. In total 3628 domestic patient and 148 international patient's reviews posted on Google and face book have been taken into consideration in the database. From the field visit in total 66 usable responses from the international patients and 94 usable responses from the domestic patient community have been received.

\subsection{Tools and Methods}

This study investigates the online image of the major healthcare hubs of the Kolkata, actively participating on the global medical tourism business. The study adopts feature-based opinion mining method of the Google place reviews and face book posts to unwrap the hidden characteristics of the major healthcare hubs of the Kolkata. The opinion sentences have been summarized based on the aspect based comments that enhances the overall data mining quality of the available comments. Along with the opinion categorisation, hospital ratings, reviews, likes, number of followers have been extracted. The opinion extraction based on the coding of the sentiments performed with the NVivo software to understand the major issues of satisfaction or dissatisfaction.

\section{RESULTS AND DISCUSSION}

\subsection{Healthcare hubs online}

In terms of overall ratings obtained from the Google and Face book indicates that most of the hospitals in Kolkata has obtained satisfactory ratings (5 out of 5). Both domestic and international patients rate service quality of Kolkata as the good one.

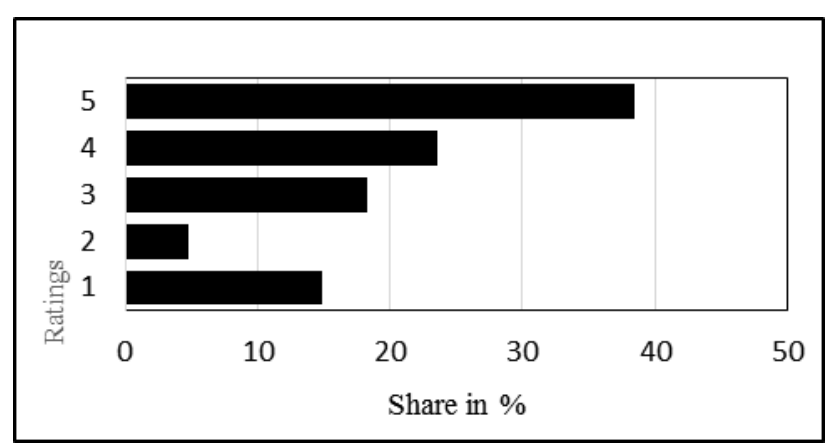

(a)

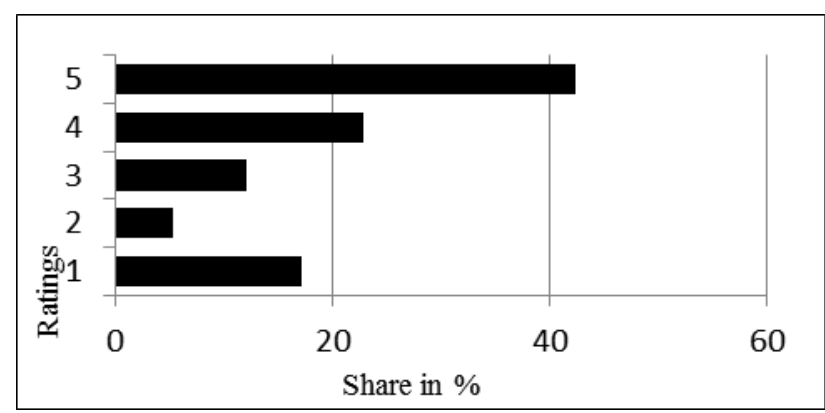

(b)

Figure 1(a) Percentage Share of Star Ratings Provided by International Patients and (b) Domestic Patients 


\begin{tabular}{|c|c|c|c|c|}
\hline \multirow{2}{*}{$\begin{array}{l}\text { Name of the } \\
\text { Hospitals }\end{array}$} & \multicolumn{3}{|c|}{ Facebook } & \multirow{2}{*}{$\begin{array}{l}\text { Google } \\
\text { Ratings } \\
\text { out of } 5\end{array}$} \\
\hline & Likes & Followers & $\begin{array}{l}\text { Ratings } \\
\text { out of } 5\end{array}$ & \\
\hline $\begin{array}{l}\text { 1. PEERLESS HOSPITAL } \\
\text { AND BK ROY RESEARCH } \\
\text { CENTRE }\end{array}$ & 56298 & 56295 & N.A & N.A \\
\hline 2. DESUN HOSPITAL & 12817 & 12817 & N.A & 3.4 \\
\hline $\begin{array}{l}\text { 3. PRIYAMBADA BIRLA } \\
\text { ARAVIND EYE HOSPITAL }\end{array}$ & 1201 & 1211 & N.A & 3.4 \\
\hline $\begin{array}{l}\text { 4. SHUSRUT EYE } \\
\text { FOUNDATION AND } \\
\text { RESEARCH CENTRE }\end{array}$ & 1912 & 1920 & 4.3 & 4.2 \\
\hline $\begin{array}{l}\text { 5. WOODLAND } \\
\text { HOSPITAL }\end{array}$ & 664 & 664 & 3.7 & 3.8 \\
\hline 6. BELLE VUE CLINIC & 363 & 366 & 3.7 & 3.7 \\
\hline $\begin{array}{l}\text { 7. NIGHTINGALE } \\
\text { HOSPITAL }\end{array}$ & 1490 & 1508 & 4 & 3.7 \\
\hline $\begin{array}{l}\text { 8. RUBY GENERAL } \\
\text { HOSPITAL }\end{array}$ & 2346 & 2354 & 4.1 & 3.7 \\
\hline $\begin{array}{l}\text { 9. APOLLO } \\
\text { GLENEAGLES HOSPITALS, } \\
\text { KOLKATA }\end{array}$ & 43058 & 43115 & 3.5 & 3.4 \\
\hline $\begin{array}{l}\text { 10. MEDICA } \\
\text { SUPERSPECIALITY } \\
\text { HOSPITAL }\end{array}$ & 22329 & 22367 & 3.7 & 3.7 \\
\hline 11. FORTIS HOSPITAL & $1 \mathrm{M}$ & $1 \mathrm{M}$ & 2.3 & 3.8 \\
\hline $\begin{array}{l}\text { 12. RN TAGORE } \\
\text { HOSPITAL MUKUNDAPUR } \\
\text { KOLKATA }\end{array}$ & 1083 & 1083 & 3.6 & 3.7 \\
\hline $\begin{array}{l}\text { 13. KOTHARI MEDICAL } \\
\text { CENTRE }\end{array}$ & 5657 & 5676 & N.A & 3.6 \\
\hline $\begin{array}{l}\text { 14. SAROJ GUPTA } \\
\text { CANCER CENTRE AND } \\
\text { RESEARCH INSTITUTE }\end{array}$ & N.A & N.A & N.A & 3.8 \\
\hline $\begin{array}{l}\text { 15. ILS HOSPITAL } \\
\text { SALTLAKE }\end{array}$ & 117577 & 117578 & 3.6 & 3.9 \\
\hline $\begin{array}{l}\text { 16. BM BIRLA HEART } \\
\text { RESEARCH CENTRE }\end{array}$ & 67,121 & 67122 & N.A & 3.8 \\
\hline $\begin{array}{l}\text { 17. AMRI HOSPITAL } \\
\text { SALTLAKE }\end{array}$ & 18231 & 18274 & 3.2 & 3.3 \\
\hline $\begin{array}{l}\text { 18. THE CALCUTTA } \\
\text { MEDICAL RESEARCH } \\
\text { INSTITUTE }\end{array}$ & 1850 & 1850 & 3.7 & 3.5 \\
\hline 19. COLUMBIA ASIA & 141 & 141 & 3.3 & 3.9 \\
\hline $\begin{array}{l}\text { 20. GENOME FERTILITY } \\
\text { CENTRE }\end{array}$ & 142392 & 142388 & 4.6 & 3.5 \\
\hline $\begin{array}{l}\text { 21. BHAGIRATI NEOTIA } \\
\text { WOMEN AND CHILD CARE } \\
\text { CENTRE }\end{array}$ & 40479 & 40525 & 4.2 & 4 \\
\hline $\begin{array}{l}\text { 22. NOVA IVI FERTILITY } \\
\text { KOLKATA }\end{array}$ & 161656 & 161857 & 4.2 & 3.9 \\
\hline
\end{tabular}

Table 2. Online profile of sample hospitals (accessed on or before 30 Jun 2017
Further to understand hospital wise scenario, the hospital wise detailed analysis of the likes, followers and hospital ratings is shown in Table 2. In terms of likes, the higher likes were obtained by the Fortis Hospital (more than 1 million) followed by Nova IVI Fertility Kolkata, Genome Fertility Centre, ILS Hospital and so on. On social media platform, The Fortis Hospital have maximum followers (1 million). In terms of mean start ratings, it is observed that most of the hospitals in Kolkata obtained mean score more than three (Figure 1a and b), except Fortis Hospital. Fortis Hospital with highest number of followers on face book obtained lowest mean star rating in compare to its counterparts. Genome Fertility Centre (mean star ratings $=4.6 / 5)$ followed by Shusrut Eye Foundation and Research Centre (4.3/5), Bhagirathi Neotia Women and Child Care Centre, Nova IVI Fertility Kolkata and Genome Fertility Care (4.2/5), Ruby General Hospital, Nightingale Hospital and others. In terms of the Google place reviews the mean star rating is again higher for the Shusrut Eye Foundation and Research Centre (4.2/5), Bhagirati Neotia Women and Child Care Centre (4/5), Nova Fertility Care (3.9/5) and others. It is observed that most of the single speciality hospital facility have created good impression online while most of the big corporate conglomerate offering multispecialty and super speciality tertiary care services failing to create positive online images.

\subsection{Demographic profile of the reviewers}

Among the samples included in the database it is found that most of response were from the male users (93.24\%) than female reviewer $(6.76 \%)$. In total responses of the international patients received from 13 countries, however overwhelmed reviews and posts were added by the patients from Bangladesh (Figure 2).

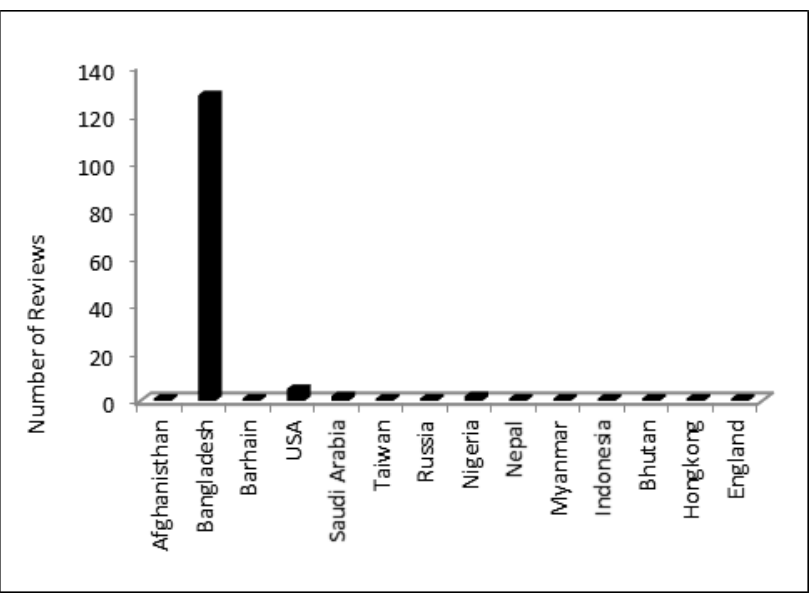

Figure 2. Nationality wise distribution of the reviews

\subsection{Treatment profile of the reviewers}

Kolkata attracts patients for the diverse treatment opportunities. It is found that in total most of the international patients choosing Kolkata for cancer care treatment (43\%) followed by preventive health check-ups (19\%), cardiology (16\%), organ transplant (9\%), diabetics and endocrinology (9\%) and urological care (Figure 3). 


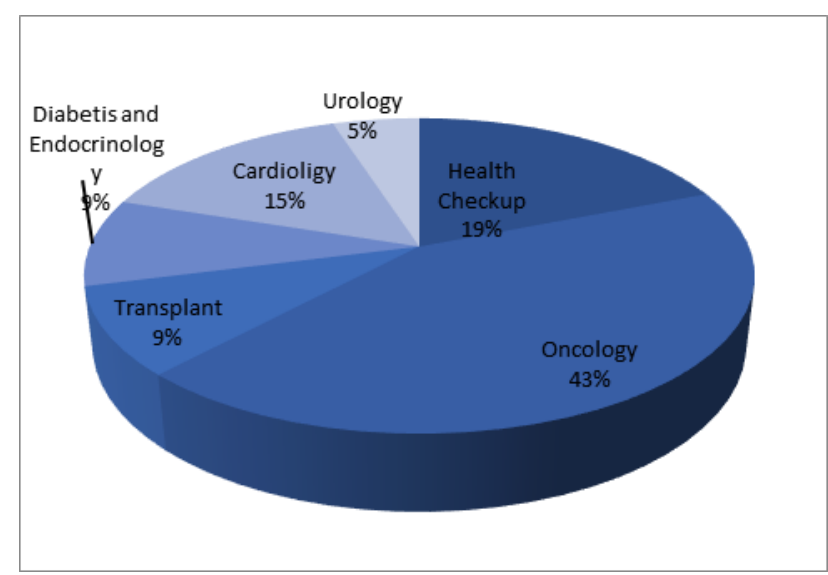

Figure 3. Treatment opted by international patients

\begin{tabular}{|c|c|}
\hline Type of Departments & Percentage (\%) \\
\hline Cardiology & 31 \\
\hline Obstetrics \& Gynecology & 12 \\
\hline Opthalmology & 8 \\
\hline Neurology & 7 \\
\hline Orthopedic & 7 \\
\hline Nephrology & 5 \\
\hline General Surgery & 5 \\
\hline General Medicine & 3 \\
\hline Gastroenterology & 3 \\
\hline Infertility care & 2 \\
\hline Diabetis and Endocrinology & 2 \\
\hline Preventive Medicine & 2 \\
\hline Oncology & 2 \\
\hline Emergency care & 1 \\
\hline Pediatric & 1 \\
\hline Health checkup & 1 \\
\hline ENT & 1 \\
\hline Bariatric Surgery & 1 \\
\hline Internal Medicine & 1 \\
\hline Diagonestic department & 1 \\
\hline Dermatology & 1 \\
\hline Dental care & 1 \\
\hline Cancer Treatment & 1 \\
\hline Department of TB & 1 \\
\hline Urology & 1 \\
\hline Hematology & 1 \\
\hline
\end{tabular}

Table 3. Medical Treatment opted by local patients

\subsection{Behavioural intentions}

On the basis of the comments posted by the reviewers aspect based opinion coding done to understand the behavioural intention of recommend or revisit to the medical facility of the Kolkata. Acknowledging the significance of the social media platform in decision making for patients, it is imperative to understand the impact of the electronic word of mouth of recommendation (eWOM) and its probable status. The result shows that on the social media platform although most of the hospitals of the Kolkata has created positive image, however AMRI Kolkata (34.38\% negative response), Apollo Gleneagles Hospital (32.96\%, negative response), Desun Hospital and Heart Institute (26.67\% negative response), Medica Superspecialty Hospital, CMRI, Columbia Asia Hospital and followed by others (as shown in Table 4) have negative image among the virtual patient community. With the very large share in the total comments posted by the reviewer online, Apollo Gleneagles Hospital needs to revisit the demand of its customers.

\begin{tabular}{|c|c|c|c|}
\hline Name of the Hospital & $\begin{array}{c}\text { Share } \\
\text { among total } \\
\text { response } \\
(\%), \\
\mathrm{N}=3768 \\
\end{array}$ & $\begin{array}{c}\text { Positive } \\
\text { Respons } \\
\text { e }(\%) \\
\end{array}$ & $\begin{array}{c}\text { Negative } \\
\text { Response } \\
(\%)\end{array}$ \\
\hline AMRI Kolkata & 6.10 & 65.61 & 34.39 \\
\hline $\begin{array}{l}\text { Apollo Gleneagles Hospitals } \\
\text { Kolkata }\end{array}$ & 14.67 & 67.04 & 32.96 \\
\hline $\begin{array}{l}\text { Desun Hospital and Heart } \\
\text { Institute }\end{array}$ & 4.70 & 72.35 & 27.65 \\
\hline Genome Fertility Care & 0.41 & 73.33 & 26.67 \\
\hline $\begin{array}{l}\text { Medica Super-specialty } \\
\text { Hospital }\end{array}$ & 7.18 & 75.77 & 24.23 \\
\hline CMRI & 7.87 & 76.84 & 23.16 \\
\hline $\begin{array}{l}\text { Columbia Asia Hospital - Salt } \\
\text { Lake }\end{array}$ & 9.81 & 77.75 & 22.25 \\
\hline $\begin{array}{l}\text { Priyamvada Birla Aravind } \\
\text { Eye Hospital }\end{array}$ & 1.38 & 78.00 & 22.00 \\
\hline Ruby General Hospital & 7.35 & 78.95 & 21.05 \\
\hline RTIICS, Kolkata & 8.59 & 79.42 & 20.58 \\
\hline ILS & 2.35 & 80.00 & 20.00 \\
\hline Nightingale Hospital & 3.87 & 80.71 & 19.29 \\
\hline Belle Vue Clinic & 5.17 & 80.75 & 19.25 \\
\hline $\begin{array}{l}\text { Indian institute of } \\
\text { Neuroscience }\end{array}$ & 5.19 & 81.38 & 18.62 \\
\hline $\begin{array}{l}\text { Saroj Gupta Cancer Research } \\
\text { Institute }\end{array}$ & 1.88 & 83.82 & 16.18 \\
\hline $\begin{array}{l}\text { Kothari Medical Centre \& } \\
\text { Research Institute }\end{array}$ & 2.27 & 84.15 & 15.85 \\
\hline $\begin{array}{l}\text { Susrut Eye Foundation \& } \\
\text { Research Centre }\end{array}$ & 1.38 & 86.00 & 14.00 \\
\hline $\begin{array}{l}\text { Woodlands Multispeciality } \\
\text { Hospital Limited }\end{array}$ & 2.10 & 86.84 & 13.16 \\
\hline $\begin{array}{l}\text { The BM Birla Heart Research } \\
\text { Centre }\end{array}$ & 4.36 & 87.34 & 12.66 \\
\hline $\begin{array}{l}\text { Peerless Hospital \& B.K. Roy } \\
\text { Research Centre }\end{array}$ & 2.21 & 90.00 & 10.00 \\
\hline Fortis Hospital & 1.16 & 90.48 & 9.52 \\
\hline
\end{tabular}

Table 4. Opinion based analysis on the virtual image of the major hospitals of the Kolkata

Among the positive image creator, it is observed that among RN Tagore Institute of Cardiac Science, Susrut Eye Foundation, Woodlands Multispeciality Hospital Limited, BM. Birla Heart Research Center, Peerless Hospital \& B.K. Roy Research 
Centre are most favorable hospital among social media community. Interestingly it is also observed that although Fortis Hospital has obtained lesser ratings among 1 million users, it is able to create positive image among electronic word-of-mouth recommendation. Further the cluster analysis of opinion indicates that most of the dissatisfaction and negative responses were associated with the service quality of the hospital staffs, long billing procedures simultaneously they are very happy with the quality and competence of the doctor. In one anonymous post one user comments:

"A nice infrastructure with highly qualified doctors and working staff. The main hall is big with facilities for stay of family members of outstation patients. With a canteen area and a temple inside the hospital campus. It is close to hotels and restaurants for fooding and lodging" : Anonymous Google User, 2017

The price sensitive patients found Kolkata more affordable than in compare to Delhi, Mumbai, and Chennai. For Bangladeshi patient lingual and cultural similarities are major attraction.

\subsection{Ground scenario}

To understand the ground scenario the present study concentrate over the level of satisfaction of the medical tourists who are visiting Kolkata and domestic patient community coming across the border of the state of West Bengal. The results found that similar to the online patient community the maximum patient visited Kolkata assigned maximum rating out of 10 to the quality of medical care received and behaviour of the paramedical staffs while most of them are not satisfied with the services offered by the non-clinical staffs involved in billing procedures and others (Table $5 \mathrm{a}$ and $\mathrm{b}$ )

\begin{tabular}{|l|l|}
\hline Factors & $8.29, \mu_{0}=8.11$ to 8.47 at $95 \%$ \\
\hline Medical Care & $9.32, \mu_{0}=9.12$ to 9.52 at $95 \%$ \\
Paramedical Staff & $6.83, \mu_{0}=6.59$ to 7.08 at $95 \%$ \\
Non -clinical staffs & $6.14, \mu_{0}=5.91$ to 6.36 at $95 \%$ \\
Fooding & $6.65, \mu_{0}=6.15$ to 7.16 at \\
Logistics & $95 \%$ \\
& $7.64, \mu_{0}=7.38$ to 7.89, at \\
Natural environment & $95 \%$ \\
& $7.33, \mu_{0}=7.15$ to 7.52 at $95 \%$ \\
Local hospitality & $8.23, \mu_{0}=8.02$ to 8.43 at \\
Overall Satisfaction level & $95 \%$ \\
\hline
\end{tabular}

Table 5 (a) Level of satisfaction among international patient community $(\mathrm{N}=66)$

\begin{tabular}{|c|c|}
\hline Factors & Mean Score of Satisfaction \\
\hline Medical Care & $7.61, \mu_{0}=7.15$ to 8.06 at $95 \%$ \\
\hline Paramedical Staff & $7.95, \mu_{0}=7.53$ to 8.36 at $95 \%$ \\
\hline Non-clinical staffs & $6.46, \mu_{0}=6.01$ to 6.90 at $95 \%$ \\
\hline fooding & $6.21, \mu_{0}=5.72$ to 6.71 at $95 \%$ \\
\hline logistics & $7.39, \mu_{0}=6.92$ to 7.87 at $95 \%$ \\
\hline $\begin{array}{l}\text { natural environment and local } \\
\text { hospitality }\end{array}$ & $4.49, \mu_{0}=3.94$ to 5.04 at $95 \%$ \\
\hline Overall Satisfaction Level & $6.19, \mu_{0}=5.76$ to 6.62 at $95 \%$ \\
\hline
\end{tabular}

Table 5 (b) Level of satisfaction among domestic patient community $(\mathrm{N}=94)$

The consensus among the image of the healthcare hubs online that is validated through field study this study uniquely highlights the dual role of internet and GIS that could together strengthen the medical tourism information system for the prospective consumer and at the same time provides significance of the crowd-sourced database with field validation that could be used by professionals and policy maker for sustenance of medical tourism which will strengthen the healthcare sector of the city in long run In fact the this study is an attempt to draw an attention of medical tourism researcher and suggest to use online social network to unwrap the many hidden pages of medical tourism and healthcare research adopting the consumer centric approach.

\section{ACKNOWLEDGEMENTS}

I am thankful to Sourav De, Sumana De, Arakmita Adhikary and Tanmoy Biswas, student and research scholar at Adamas University for their intensive cooperating during database creation. 
The International Archives of the Photogrammetry, Remote Sensing and Spatial Information Sciences, Volume XLII-5, 2018 ISPRS TC V Mid-term Symposium "Geospatial Technology - Pixel to People", 20-23 November 2018, Dehradun, India

\section{REFERENCES}

[1] J. W. Munro, "Best Practices in Medical Tourism - What is Medical Tourism," 2012. [Online]. Available: www.mtqua.org. [Accessed 5 October 2014].

[2] P. S. Cook, "Constructions and Experiences of Authenticity in Medical Tourism: The Performances of Places, Spaces, Practices, Objects and Bodies," Tourist Studies, vol. 10, no. 2, p. 135-153, 2010.

[3] W. C. Hunter, "Medical Tourism: A Global Niche," vol. 7, no. 1, pp. 129 - 140, 2007.

[4] L. Turner, "First World Health Care at Third World Prices: Globalization, Bioethics and Medical Tourism," BioSocieties , vol. 2, p. 303-325, 2007.

[5] T. Ehrbeck, G. C and M. P. D, "Mapping the World for Medical travel," archived from https://www.mckinseyquarterly.com/, May 2008

[6] S. Tata, "Medical travel in Asia and the Pacific Challenges and Opportunities," United Nations Economic and Social Commission for Asia and the Pacific (ESCAP) 63rd Commission Session, Bangkok, 2009.

[7] G. Eysenbach and K. C, "What is prevalence of health - related Searches on the World Wide Web? Qualitative and Quantitative analysis of search engine queries on the Internet," in AMIA 2003 Symposium Proceedings, 2003.

[8] S. Moghavvemi, M. Ormond, G. Musa, C. R. M. Isa, T. Thirumoorthi, M. Z. B. Mustapha, K. A. Kanapathy and J. J. C. Chandy, "Connecting with prospective medical tourists online: A cross-sectional analysis of private hospital websites promoting medical tourism in India, Malaysia and Thailand," Tourism Management, vol. 58, pp. 154-164, 2016.

[9] S. Donnely, 2017. [Online]. Available: https://www.quora.com/What-is-the-importance-of-social-media-in-our-daily-life. [Accessed 06 August 2018].

[10] Anissa, 9 March 2017. [Online]. Available: http://www.designneesh.com/the-value-of-google-reviews-vs-facebookreviews-vs-yelp-reviews-on-which-one-is-right-for-you/. [Accessed August 2018].

[11] A. Rai, P. Chakraborty and A. Sarkar, "India as a Medical Tourism Hub in SAARC - a geographical analysis," Indian Journal of Spatial Science, 2014.

[12] P. Foote, 2017. [Online]. Available: https://www.modul.ac.at/index.php?eID=dumpFile\&t=f\&f=9381\&token=fb953aac92b9303ca7c5454280c8c55aa1e217bf. [Accessed 2018].

[13] Y. Hallem and I. Barth, "Understanding the role of internet in explaining the medical tourists behaviour: a conceptual model," Management Prospective Ed., pp. 51-69, 2015.

[14] M. S, O. M, M. G, I. R. Mohamed, T. Thirumoorthi, M. Z. B. Mustapha, K. A. K and J. Chandy, "Connecting with prospective medical tourists online: A cross-sectional analysis of private hospital websites promoting medical tourism in India, Malaysia and Thailand,” Tourism Management, vol. 58, pp. 154 - 163, 2017.

[15] D. Horsfall, N. Lunt, H. King, J. Hanefeld and R. D. Smith, "The imapct of internet on medical tourism," Medical Tourism and Transnational Health Care, pp. 223 - 239, 2013.

[16] A. Ertugan., "Using statistical reasoning techniques for measuring users emotional connectedness to Facebook and their altitude towards Facebook advertiseing," Procedia, 2016

[17] A. Medhekar, "The Role of Social Media for Knowledge Dissemination in Medical Tourism: A Case of India," Harnessing Social Media as a Knowledge Management Tool, p. 30, 2017.

[18] M. DiStasoa, M. Vafeiadisb and C. Amaral, "Managing a health crisis on Facebook: How the responsestrategies of apology, sympathy, and information influence public relations," Public Relations Reviews, 2014

[19] J. Liu, C. Li, G. Y. Ji, M. North and F. Yang, "Like it or not: The Fortune 500's Facebook strategies to generate users'electronic word-of-mouth," Computers in Human Behavior, vol. 73, pp. 605-613, 2017.

[20] M. Mariania, M. Murab and M. Felicec, "The determinants of Facebook social engagement for national tourism organizations' Facebook pages: A quantitative approach,” Journal of Destination Marketing \& Management, 2017.

[21] N. Rajendhiran and M. Devi, “Social Media Marketing in Healthcare and Medical Tourismin India,” 2014.

[22] A. Rai, Medical tourism in Kolkata, Eastern India, Springer International, 2019

[23] D. Boyd and N. Ellison, "Social network sites: Definition, history, and scholarship.," Journal of Computer-Mediated Communication, , vol. 13, p. 210-230, 2008.

[24] J. K. Ayeh, N. Au and R. Law, "Predicting the intention to use consumer-generated media for travel planning.," Tourism Management, , vol. 35, p. 132-143, 2013.

[25] R. Schegg, A. Liebrich, M. Scaglione and S. F. S. Ahmad, "An exploratory field study of web 2.0 in tourism.," Information and Communication Technologies in Tourism, vol. 5, p. 152-163, 2008.

[26] N. Cortez, "Patients Without Borders: The Emerging Global Market for Patients and the Evolution of Modern Heath care," Indiana Law Journal, vol. 83, no. 1 , p. 71 - 132, 2008.

[27] S. Edosomwan, S. K. Prakasan, D. Kouame, J. Watson and T. Seymour, "The History of Social Media and its Impact on Business," The Journal of Applied Management \& Entrepreneurship, vol. 16, no. 3, pp. 79-91, January 2011. 